\title{
Acute kidney injury requiring renal replacement therapy due to severe hemolysis after mechanical thrombectomy
}

\author{
Puneet Bedi, Daniel Addanki, Aaron Reichman, Shyan-Yih Chou, Ira Reiser \\ Brookdale University Hospital and Medical Center, Brooklyn, New York, USA
}

Received: September 20, 2016

Accepted: October 16, 2016

Online Published: October 23, 2016

DOI: $10.5430 /$ crim.v3n4p87

URL: http://dx.doi.org/10.5430/crim.v3n4p87

\begin{abstract}
Deep vein thrombosis is a frequently encountered medical condition, and one that is associated with significant morbidity if not promptly diagnosed and treated. Anticoagulation alone is, at times, insufficient for recanalization, particularly in those patients with ileofemoral thromboses. Pharmacomechanical catheter-directed thrombolysis has been used for clot dissolution and removal in these cases. Although hemolysis could occur due to mechanical lysis of red blood cells during the procedure, acute kidney injury has seldom been reported. We now report a case of massive hemoglobinuria that occurred immediately after the use of a pharmacomechanical catheter-directed technique to dissolve large deep vein thrombi. Severe oliguric acute renal failure ensued, complicated by uremic pericarditis and requiring four sessions of hemodialysis therapy.
\end{abstract}

Key Words: Acute kidney injury, Heme nephropathy, Mechanical thrombectomy

\section{INTRODUCTION}

Deep vein thrombosis (DVT) is a commonly encountered medical problem with an average annual incidence of 95 per 100,000 in the general population. ${ }^{[1]}$ Both pulmonary embolism and the post-thrombotic syndrome may result as a consequence of a DVT. Prompt recognition and therapy of DVT is essential to prevent these sequelae; however, complete venous recanalization rarely occurs in ileofemoral DVTs with standard anticoagulant therapy. To improve recanalization, mechanical thrombectomy devices have increasingly been used in selected patients with acute venous thromboembolic disease to rapidly decrease thrombus burden and establish venous patency. Recently, catheter-directed thrombolysis (CDT) and pharmacomechanical catheter-directed thrombolysis (PCDT) have also been developed for thrombus removal.
One such device, the Angiojet Rheolytic Thrombectomy Catheter System (Possis Medical, Minneapolis, MN) allows for both the instillation of thrombolytic agents and mechanical thrombectomy to be performed during thrombus removal. With its "power pulse" technique the thrombolytic agent is allowed to bathe the clot for 20-45 minutes, thereby softening the thrombus. To perform thrombectomy, the device selectively traps, solubilizes and dissipates a thrombus via hydraulic whirl. Hemolysis caused by the mechanical force is a potential complication and has been observed in animal and human studies after mechanical thrombectomy. ${ }^{[2,3]}$ Transient acute kidney injury, caused by either hemoglobinuria or radiocontrast, has also been described. ${ }^{[2]}$ We now report a case of prolonged acute kidney injury due to hemoglobinuria following the dissolution of a DVT with the use of the

\footnotetext{
*Correspondence: Puneet Bedi, MD; Email: puneetbedi11@ gmail.com; Address: Brookdale University Hospital and Medical Center, Brooklyn, New York, USA.

Published by Sciedu Press 
Angiojet Rheolytic Thrombectomy Catheter System.

\section{CASE}

A 52-year-old African-American woman presented to the Emergency Room with worsening pain in the left knee over the preceding 5 days, associated with nausea, vomiting, chills and fever. On physical examination, she was afebrile; the pulse rate 110 beats/minute and the blood pressure 104/56 mmHg. Aside from swelling, erythema and limited range of motion of her left knee the remainder of the examination was unremarkable. Initial laboratory data demonstrated a WBC count of $16.3 \times 10^{9} / \mathrm{L}$, a hemoglobin concentration of $10.7 \mathrm{~g} / \mathrm{dl}$, and a BUN and creatinine level of 22 and 0.9 $\mathrm{mg} / \mathrm{dl}$, respectively. The serum D-dimer level was elevated $(2,138 \mathrm{ng} / \mathrm{ml})$. A Doppler study of her left lower extremity showed a negative result for DVT; however, a subsequent venogram of the left lower extremity revealed acute thrombi in both the superficial and deep venous system of her left lower extremity. There was occlusion of the saphenous vein in the mid-to-lower thigh, an extensive filling defect in the femoral vein traversing the thigh and a free floating thrombus in the inferior vena cava (IVC). A CT scan revealed enlargement of the left iliac vein with abrupt narrowing posterior to the right common iliac artery, findings consistent with extensive DVT in the left lower extremity in the presence of left iliac vein compression (May-Thurner Syndrome). Catheterdirected thrombolysis with TPA in conjunction with iliac vein stenting was attempted, but was terminated because of bleeding.

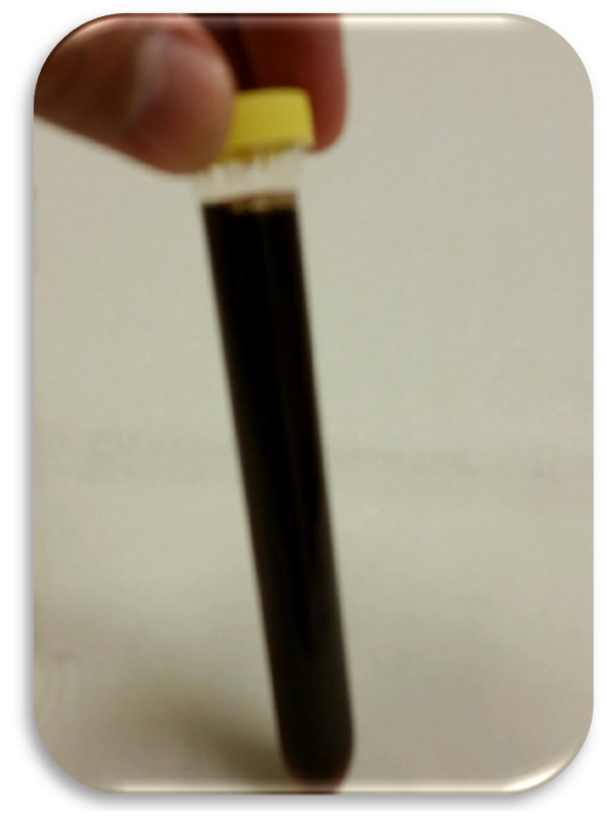

Figure 1. Hemoglobinuria noted within few hours of procedure
Since there was only partial resolution of the clots, a decision was made to proceed with PCDT with the use of the Angiojet Rheolytic Thrombectomy Catheter System (Possis Medical, Inc. Minneapolis, MN). The clot was initially laced with Alteplase. After approximately a 45-minute dwell time, mechanical thrombectomy was performed for about ten minutes with aspiration of $400 \mathrm{ml}$ of thrombus. Dilatation and stenting of the left common iliac vein and inferior vena cava using overlapping Wallstents was also undertaken. Within 4 hours after the procedure the patient was noted to have discolored urine (see Figure 1) and became oliguric. The urinalysis demonstrated 4+ blood; however, the urinary sediment was notable for the absence of RBCs and presence of many pigmented casts (see Figure 2). Her serum creatine kinase level was $355 \mathrm{U} / \mathrm{L}$. One day after the procedure, she was anuric and the serum creatinine concentration had increased from 0.8 to $2.6 \mathrm{mg} / \mathrm{dl}$. The results of additional laboratory tests are summarized in Table 1.

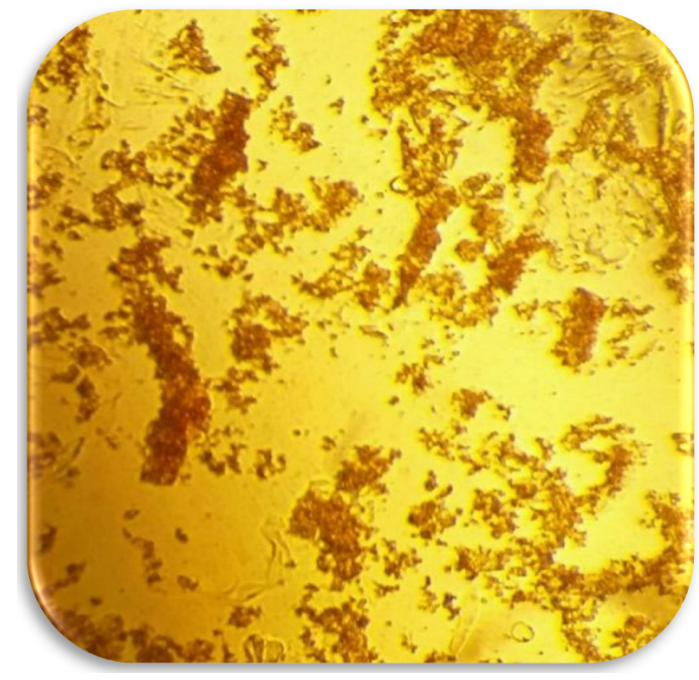

Figure 2. Heme pigment casts in the urine under light microscopy ( $\times 400$ magnification)

Given these findings, it was felt that her acute kidney injury was the result of heme toxicity and heme cast formation due to intravascular hemolysis associated with the AngioJet procedure, rather than from exposure to her radiocontrast administration since she had been vigorously hydrated with normal saline at $150 \mathrm{ml} / \mathrm{hr}$ the 48 hours prior to undergoing the contrast studies. A non-oliguric state was achieved following the administration of a high dose of furosemide; however, the patient remained in established renal failure. Her peak serum creatinine concentration was $8.7 \mathrm{mg} / \mathrm{dl}$ at day 8 post-procedure and at day 11 she was found to have a pericardial friction rub. Anticoagulation was discontinued and hemodialysis was initiated. After 4 sessions of hemodialysis, the pericarditis resolved and she subsequently entered 
into the diuretic recovery phase of acute renal failure, requiring no further dialysis. Her renal function fully recovered 28 days after the mechanical thrombectomy, and the serum creatinine level was $0.7 \mathrm{mg} / \mathrm{dl}$ at discharge.

Table 1. Pre and post procedure labs

\begin{tabular}{llll}
\hline Lab & Reference range & Pre procedure & $\begin{array}{l}\text { Within 24 hours } \\
\text { post procedure }\end{array}$ \\
\hline WBC & $(4.8-10.8) 10^{9} / \mathrm{L}$ & 20.9 & 22.6 \\
RBC & $(4.00-5.20) 10^{12} / \mathrm{L}$ & 3.20 & 2.66 \\
Hemoglobin & $(12.2-15.3) \mathrm{g} / \mathrm{dl}$ & 8.20 & 7.2 \\
Platelet & $(150-400) 10^{9} / \mathrm{L}$ & 696 & 519 \\
BUN & $(7-25) \mathrm{mg} / \mathrm{dl}$ & 18 & 38 \\
Creatinine & $(0.50-1.50) \mathrm{mg} / \mathrm{dl}$ & 0.8 & 2.6 \\
Potassium & $(3.5-5.0) \mathrm{mEq} / \mathrm{L}$ & 4.6 & 5.1 \\
CPK & $(20-200) \mathrm{U} / \mathrm{L}$ & 36 & 355 \\
AST & $(11-42) \mathrm{U} / \mathrm{L}$ & 20 & 112 \\
ALT & $(0-20) \mathrm{U} / \mathrm{L}$ & 19 & 14 \\
LDH & $(313-618) \mathrm{IU} / \mathrm{L}$ & 992 & 6,340 \\
Haptoglobin & $(43-212) \mathrm{mg} / \mathrm{dl}$ & 686 & 87 \\
\hline
\end{tabular}

\section{Discussion}

PCDT was developed to address the limitation of CDT in clot dissolution by combining delivery of a thrombolytic medication with catheter-based mechanical technology to dissolve thrombi, followed by aspiration of the blood clots. The Angiojet Rheolytic Thrombectomy with a Variety of Catheter Lengths (PEARL) registry was first established to document the procedural and patient outcomes following the endovascular treatment of arterial and venous thromboses with the AngioJet Thrombectomy Catheter System. ${ }^{[3]}$ Within the registry, 329 patients with normal renal function were treated for lower extremity DVT, the majority of whom had involvement of the iliac and femoral veins $(66 \%$ and $89 \%$, respectively). Only one patient developed acute renal failure, requiring dialysis following the procedure. This patient featured bilateral DVT, a history of diabetes mellitus and had an extended Angiojet time of 18.5 minutes (the average run time in the registry was $7.2 \pm 6.3$ minutes) in addition to receiving $240 \mathrm{ml}$ of intravenous radiocontrast during the procedure.

Two other cases of reversible acute renal failure which required renal replacement therapy have been reported in the literature following PCDT with Angiojet. The first was a 43-year-old pregnant woman at 8 weeks gestation and was found to have bilateral mainstem pulmonary artery emboli. She underwent thrombectomy with the use of the AngioJet and developed oliguric acute renal failure due to hemolysis and heme pigment nephropathy. ${ }^{[4]}$ The second case involved

Published by Sciedu Press a 16-year-old woman who had an occlusive thrombus in the IVC extending into the right common iliac vein and a pulmonary embolism associated with antiphospholipid syndrome and a hypercoaguable state. Following PCDT with AngioJet to remove the thrombi in the IVC and iliac vein, the patient developed acute renal failure, attributed to hemolysis and hemoglobinuria. ${ }^{[5]}$ In both of these cases, similar to our patient, renal function returned to normal after a period of 3-4 weeks following the PCDT. A case of protracted acute renal failure following PCDT has also been described. In this particular case, following PCDT of an extensive lower extremity DVT, the patient was found to have oliguric acute renal failure due to hemoglobinuria 6 days after the procedure and required ongoing maintenance hemodialysis 5 months after the mechanical thrombectomy. ${ }^{[6]}$

The mechanisms whereby the heme pigment causes nephrotoxicity have been extensively studied. These include hemeinduced renal vasoconstriction, pigment cast formation in the renal tubules, and direct heme protein-induced cytotoxicity. ${ }^{[7]}$ Studies in rats have demonstrated that infusion of myoglobin, which contains a heme prosthetic group, not only lowers baseline adenylate pools in the absence of shock but also markedly accentuates the shock-induced adenylate depletion by a non-hemodynamic or non-ferric dependent mechanism. ${ }^{[8,9]}$

Although it has been postulated that cast formation can directly impair glomerular filtration via tubular obstruction and increased intratubular pressures, this has been challenged in several studies. ${ }^{[10-12]}$ Observations based upon these studies have led investigators to conclude that a reduction in glomerular filtration rate occurs as a result of an increase in preglomerular resistance rather than by tubular obstruction by pigmented casts. Heme cast formation, however, can still play a critical role in the induction of tubular necrosis by extending the period of proximal tubular heme endocytic transport and increasing proximal tubular cell heme exposure and toxicity as discussed below.

Heme can directly affect various cellular targets and induce nephrotoxicity. Bunn and Jandl noted that in the circulation hemoglobin can rapidly dissociate into $\alpha$ and $\beta$ dimers, halving its size, thus allowing rapid glomerular filtration and reabsorption of heme by the proximal tubular cell via endocytosis. ${ }^{[13]}$ Here, the porphyrin ring derived from the heme protein is catabolized, releasing its iron content. Iron, a transition metal that can readily accept or donate electrons, can facilitate free radical ion production and promote cell injury. ${ }^{[14,15]}$ Nath and co-workers found that heme, in the serum-deficient condition, induces caspase- 3 expression and apoptosis, while in the presence of serum can upregulate 
p21, a cyclin-dependent kinase inhibitor, and induce cell cycle arrest and inhibit cell growth. ${ }^{[16]}$ Heme can oxidize lipids, denature proteins, and perturb the integrity of the cellular cytoskeleton. ${ }^{[17]}$ Heme exposure can also degenerate mitochondria, affect cellular respiration and damage DNA. ${ }^{[18]}$ Thus, heme nephrotoxicity can result in cell cycle arrest, cellular apoptosis and cause structural damage to various cellular organelles and result in acute kidney injury. These animal study findings can be extrapolated to explain how our patient developed protracted renal injury after mechanical thrombectomy due to heme exposure, despite being hemodynamically stable and having a normal baseline serum creatinine concentration.

Although PCDT with Angiojet has been shown to be effective in solubilizing and removing thrombi or emboli, it appears that the size of the clot and duration of the procedure may significantly affect the degree of hemolysis and the potential for hemoglobin-induced nephrotoxicity. Similar to the cases previously cited, our patient had a large clot burden which led to a prolonged procedure time and significant hemolysis, resulting in hemoglobin-induced nephrotoxicity and acute renal failure. Thus, when employing PCDT technology in the management of thrombi or emboli, particularly in those who have a larger clot burden, clinicians should be aware of the potential risk of acute kidney injury.

\section{CONFlicts of Interest Disclosure}

The authors have declared no conflicts of interest.

\section{REFERENCES}

[1] Spencer FA, Emery C, Joffe SW, et al. Incidence rates, clinical profile, and outcomes of patients with venous thromboembolism. The Worcester VTE study. J Thromb Thrombolysis. 2009; 28: 401-409. PMid:19629642 http://dx.doi.org/10.1007/s11239-009-0 378-3

[2] Cynamon J, Stein EG, Dym J, et al. A new method for aggressive management of deep vein thrombosis: Retrospective study of the power pulse technique. J Vasc Interv Radiol. 2006; 17: 1043-1049. PMid:16778240 http://dx.doi.org/10.1097/01. RVI. 0000221085.25333 .40

[3] Garcia MJ, Lookstein R, Malhotra R, et al. Endovascular Management of Deep Vein Thrombosis with Rheolytic Thrombectomy: Final Report of the Prospective Multicenter PEARL (Peripheral Use of AngioJet Rheolytic Thrombectomy with a Variety of Catheter Lengths) Registry. J Vasc Interv Radiol. 2015; 26(6): 777-85. PMid:25824314 http://dx.doi.org/10.1016/j.jvir.2015.01.036

[4] Dukkipati R, Yang EH, Adler S, et al. Acute kidney injury caused by intravascular hemolysis after mechanical thrombectomy. Nat Clin Pract Nephrol. 2009; 5(2): 112-6. PMid:19092794 http: //dx.doi.org/10.1038/ncpneph1019

[5] Arslan B, Turba UC, Matsumoto AH. Acute renal failure associated with percutaneous mechanical thrombectomy for iliocaval venous thrombosis. Semin Intervent Radiol. 2007; 24(3): 288-95. PMid:21326470 http://dx.doi .org/10.1055/s-2007-98573 6

[6] Mathews JC, Pillai U, Lacasse A. Prolonged renal failure postpercutaneous mechanical thrombectomy. NDT Plus. 2011; 4: 241 243. http://dx.doi.org/10.1093/ndtplus/sfr050

[7] Zager RA. Heme protein-ischemic interactions at the vascular, intraluminal, and renal tubular cell levels: Implications for therapy of myoglobin-induced renal injury. Renal Failure. 1992; 14: 341-344. http://dx.doi.org/10.3109/08860229209106640

[8] Vetferlein R, Hoffmann F, Pedina J, et al. Disturbances in renal microcirculation induced by myoglobin and hemorrhagic hypotension in anesthetized rat. Am J Physiol. 1995; 268: F839-F846.
[9] Zager RA. Myoglobin depletes renal adenine nucleotide pools in the presence and absence of shock. Kidney Int. 1991; 39: 111-119. http://dx.doi.org/10.1038/ki.1991.14

[10] Oken DE, Arce ML, Wilson DR, et al. Glycerol-induced acute renal failure in the rat. I. Micropuncture study of the development of oliguria. J Clin Invest. 1966; 45: 724-735. PMid:5935360 http://dx.doi.org/10.1172/JCI105387

[11] Ruiz-Guinazu A, Coelho JB, Paz RA. Methemoglobin-induced acute renal failure in the rat. Nephron. 1967; 4: 257-275. PMid:6064790 http://dx.doi.org/10.1159/000179587

[12] Jaenike JR. Micropuncture study of methemoglobin-induced acute renal failure in the rat. J Lab Clin. Med. 1969; 73: 459-468. PMid:5766190

[13] Bunn HF, Jandl JH. The renal handling of hemoglobin. II Catabolism J Exp Med. 1969; 129: 925-934. http://dx.doi.org/10.1084 /jem.129.5.925

[14] Aust SD, Morehouse LA, Thomas CE. Role of metals in oxygen radical reactions. J Free Radical Biol Med. 1985; 1: 3-25. http://dx.doi.org/10.1016/0748-5514(85)90025-X

[15] Cross CE, Halli Well B, Borish ET, et al. Oxygen radicals and human disease. Ann Intern Med. 1987; 107: 526-545. PMid:3307585 http://dx.doi.org/10.7326/0003-4819-107-4-526

[16] Gonzalez-Michaca L, Farrugia G, Croatt AJ, et al. Heme: A determinant of life and death in renal tubular epithelial cells. Am J Physiol Renal Physiol. 2004; 286: F370-F377. PMid:14707007 http://dx.doi.org/10.1152/ajprenal.00300.2003

[17] Hebbel RP, Eaton JW. Pathobiology of heme interaction with the erythrocyte membrane. Semin Hematol. 1989; 26: 136-149. PMid:2658089

[18] Nath KA, Grande JP, Croatt AJ, et al. Intracellular targets in heme protein-induced renal injury. Kidney Int. 1998; 53: 100111. PMid:9453005 http://dx.doi.org/10.1046/j.1523-1 $755.1998 .00731 . x$ 